Specialty care in the community

\section{Quality care in the community: the Rt Hon Sir Menzies Campbell MP, Leader of the Liberal Democrats}

\section{Maximising the independence of patients}

$\mathrm{T}$ his is an excellent initiative from the Postgraduate Medical Journal.

Quality care in the community is vital to ensure that patients maximise their independence after discharge from hospital, or when managing a chronic condition. I welcome an approach that would offer hospital doctors the opportunity to broaden their understanding of how people with such conditions can be supported in the community.

\section{The educational needs of doctors delivering specialist services in the community}

\section{Liam Donaldson, Chief Medical Officer}

\section{Underpinning service development with education and training programmes}

$7 \mathrm{~g}$ he sharp division between specialist services provided in hospitals and generalist services provided in the community has become firmly institutionalised in the National Health Service. Patients do not recognise artificial demarcations between sectors in the way that many professionals do; what they want is coordinated, safe, high-quality services delivered, whenever possible, as close to their homes as possible by well-trained and committed health professionals. Two key educational challenges flow from this analysis.

Firstly, we need to focus on ensuring that there are clear and explicit standards underpinning the provision of specialist care in community settings. These standards need to reflect both the generic skills required to provide high-quality care (such as communication, leadership, teamwork and an understanding of the scientific basis of quality improvement), and the specific skills required to undertake whatever specialised practices might be moved into the community.

There must be no compromise on either the quality or the safety of care when more services are moved out of hospitals. Indeed, the commissioning of new services in the community provides an opportunity to set even more rigorous standards of quality and safety than exist at present. From an educational perspective, this will require a commitment to locating a higher proportion of training in the community at both undergraduate and postgraduate levels. It will also require a continuing commitment to quality improvement through appraisal, re-licensure and recertification, as I set out in my recent report on medical regulation. ${ }^{1}$ This will present a significant challenge to the royal colleges and professional societies, the regulatory authorities, the universities and the postgraduate deaneries.
The Liberal Democrats advocate a "joined up" approach between the National Health Service and social care services to encourage good communication among general practitioners, social services and the local hospital, and to ensure the best quality care for each individual.

As it becomes possible for doctors to conduct more sophisticated investigations outside the hospital environment, such a scheme could ensure that more patients are supported in the community without needing to be admitted to hospital. This would reduce waiting times for hospital appointments and admissions, and free up much needed hospital beds for patients who do need to be admitted. I welcome this initiative.

Postgrad Med J 2007;83:3 doi: $10.1136 /$ pgmi.2006.055715

Secondly, we need to recognise the unique characteristics of healthcare in the community. While specialist technical procedures might be the same whether they are carried out in hospital or in primary care settings, the context is very different. Clinicians used to working in primary care are experienced and skilled at dealing with early undifferentiated symptoms and signs, coping with uncertainty, using time as well as technical interventions as therapeutic tools and managing complex comorbidity. It is essential that generalists who might provide specialist care, such as general practitioners or pharmacists with special interests, do not lose those skills, and that specialists working in community settings understand the value of generalism and how it complements specialist practice.

Providing a higher proportion of specialised services in the community presents unique educational challenges. In a truly integrated and patient-centred healthcare system, service development must be underpinned by education and training programmes to prepare practitioners for the opportunities that are opened up.

Postgrad Med J 2007;83:3.

doi: 10.1136/pmi.2006.055707

\section{REFERENCE}

Donaldson L. Good doctors, safer patients: proposals to strengthen the system to assure and improve the performance of doctors and to protect the safety of patients. London, Department of Health, 2006 www.dh.gov.uk (accessed 7 December 2006). 